\title{
Release of glucose by Nostoc spec. isolated from the lichen Peltigera horizontalis
}

\author{
Doris Meindl and Eckhard Loos \\ Lehrstuhl ftir Zellbiologie und Pflanzenphysiologie, Universitätssrasse 31, Universität Regensburg, D-8400 Regensburg (F.R.G.)
}

(Received March 23rd, 1990; revision received July 27th, 1990; accepted July 27th, 1990)

Cultured Nostoc spec. from Peltigera horizontalis excreted in the light between $1 \%$ and $3.4 \%$ of fixed ${ }^{14} \mathrm{CO}_{2}$ into the medium, $\leqslant 0.8 \%$ as glucose. A several-fold increase in the rate of release was caused by addition of carbonyl cyanide $p$-trifluoromethoxyphenylhydrazone (FCCP) in the dark, the major component released being glucose. The amount of glucose excreted in the presence of FCCP exceeded the pool of intracellular glucose + glucose 6-phosphate by far, suggesting a glucan as a precursor. A glucan - identified enzymatically with amyloglucosidase - was the main assimilation product which was degraded during excretion of glucose in the dark in the presence of FCCP. Of the free-living cyanobacteria, Nostoc punctiforme also showed glucose release whereas Nostoc muscorum did not. It is concluded that (i) the symbiotic Nostoc spec. can excrete glucose in the absence of the fungal partner, (ii) this release is a passive process being fed by a glucan and (iii) glucose release is not a specific function of symbiotic cyanobacteria.

Key words: cyanobacteria (Nostoc); glucose transport; lichen (Peltigera); symbiosis

\section{Introduction}

Glucose is believed to move in substantial amounts ( $>33 \%$ of photosynthate) from Nostoc spec. to the fungal partner in the thallus of Peltigera polydactyla $[1,2]$, a process which seems to be common to most cyanobacteria-containing lichens [3]. Only small amounts of labeled glucose, however, appeared in the medium when Nostoc spec. was allowed to assimilate ${ }^{14} \mathrm{CO}_{2}$ immediately after isolation from Peltigera canina $3.4 \%$ of total label); $3 \mathrm{~h}$ after isolation, or upon culturing the cells, no radioactivity at all could be detected in this sugar [4, cf. 5]. Obviously, in the intact lichen, glucose excretion of the alga is induced somehow by the fungal partner [4]. As a starting point to unravel this fascinating regulatory phenomenon, the excretion characteristics of a cultured symbiotic cyanobacterium were studied. In

Correspondence to: Eckhard Loos, Lehrstuhl für Zellbiologie und Pflanzenphysiologie, Universitätsstrasse 31, Universität Regensburg, D-8400 Regensburg, F.R.G.

Abbreviation: FCCP, carbonyl cyanide p-trifluoromethoxyphenyl hydrazone. the present work the isolation and growth of Nostoc spec. from Peltigera horizontalis are briefly described and conditions for glucose release reported. Furthermore, two free-living cyanobacterial species were tested for glucose release, to see whether this is a specific feature of symbiotic bluegreen algae.

\section{Material and Methods}

\section{Plant material}

Nostoc spec. was isolated from Peltigera horizontalis growing on woody cliffs $15 \mathrm{~km}$ southwest of Regensburg, F.R.G. Algal filaments were removed from thallus cuts with a fine needle, suspended in a mineral nutrient medium described by Matzke et al. [6] and sonicated in an ultrasonic bath to obtain short fragments. After repeated washings with sterile medium the cell material was plated on the same medium solidified with $1 \%$ agar. After incubation for $1-2$ weeks at $28^{\circ} \mathrm{C}$ at $3000 \mathrm{~lx}$ colonies appeared which were transferred to fresh agar medium. Axenic colonies were identified by microscopic examination and by plating 
on a complex medium ( $1 \%$ peptone, $0.5 \%$ yeast extract, $0.2 \%$ glucose, $1 \%$ agar). Cultures were maintained on medium BG-11 [7] containing 1\% agar and were incubated at room temperature near a window shaded from sunlight. Liquid cultures were raised in medium BG11 [7] in which $\mathrm{NaNO}_{3}$ was replaced by $1 \mathrm{mM} \mathrm{NaCl}$; other conditions were as described previously [8]. Cells were harvested by centrifugation 9-13 days after inoculation when a density between 45 and $90 \mathrm{~g} / 1$ wet weight had been reached corresponding to $1.2-$ $2.4 \mathrm{~g} / \mathrm{l}$ dry weight. Nostoc muscorum and Nostoc punctiforme were obtained from Sammlung für Algenkulturen, Göttingen, F.R.G. The latter species was purified from contaminating bacteria, cultured and harvested as outlined above for the Nostoc spec. from Peltigera.

Incubation of Nostoc spec. with ${ }^{14} \mathrm{CO}_{2}$; estimation of ${ }^{14} \mathrm{C}$ incorporation and excretion; analysis of labeled excretion products

Routinely, filaments of $30 \mathrm{mg}$ wet weight were washed and suspended in $0.5 \mathrm{ml} 50 \mathrm{mM}$ citric acidtrisodium citrate buffer ( $\mathrm{pH} 4.8$ ) in a closed 5-ml vial containing an atmosphere of $0.9 \%{ }^{14} \mathrm{CO}_{2}$ (by vol.) in air with a specific radioactivity of $7.4 \mathrm{kBq}$ - $\mu \mathrm{mol}^{-1}$. The cells were incubated for $1 \mathrm{~h}$ with shaking in a water bath at $260 \mathrm{rev} . / \mathrm{min}, 28^{\circ} \mathrm{C}$ with an illuminance of $150001 \mathrm{x}$. At the end of the incubation period cells were separated from the medium by centrifugation and the incorporated radioactivity was determined after hydrolysis $(2 \mathrm{~h}$ in $2 \mathrm{M}$ trifluoroacetic acid, $120^{\circ} \mathrm{C}$ ) by scintillation counting. The radioactivity of the medium was also measured by scintillation counting and further analysis was carried out by thin-layer chromatography of the desalted medium, employing a TLC-scanning device (LB 284 from Berthold, Wildbad, F.R.G). Details of the procedure have been published elsewhere [8].

\section{Determination of glucose; preparation of aqueous cell extracts}

Glucose was determined enzymatically with the hexokinase/glucose-6-phosphate dehydrogenase system [9]. Aqueous cell extracts were obtained in principle by the method of Bieleski [10] by incubating $1-2 \mathrm{~g}$ wet weight cells in a mixture of
$\mathrm{CH}_{3} \mathrm{OH} / \mathrm{CHCl}_{3} / \mathrm{H}_{2} \mathrm{O} / \mathrm{HCOOH}$ (12:5:2:1, by vol.) overnight at $-20^{\circ} \mathrm{C}$. After shaking and phase separation the aqueous phase was concentrated under reduced pressure, made $80-90 \%$ (by vol.) with respect to acetone to precipitate phycobiliproteins and then evaporated to dryness. The material was resuspended in water and clarified by centrifugation. The $\mathrm{pH}$ was adjusted to neutrality before glucose + glucose 6-phosphate were determined with the hexokinase/glucose-6-phosphate dehydrogenase system [9].

\section{Determination of labeled insoluble material and glucan}

${ }^{14} \mathrm{C}$-Labeled cells (60 $\mathrm{mg}$ wet weight) were extracted twice with $3 \mathrm{ml} 80 \%$ ethanol $(\mathrm{v} / \mathrm{v})$ at $60^{\circ} \mathrm{C}$, the residue was homogenized in $80 \%$ ethanol $(\mathrm{v} / \mathrm{v})$ by sonication for $3 \mathrm{~min}$ with the microtip of a Branson sonifier (Danbury, U.S.A.) set to $35 \mathrm{~W}$ output followed by vortexing for $5 \mathrm{~min}$ with a mixture of $1.3 \mathrm{~g}$ glass beads $(0.5 \mathrm{~mm}$ diameter) $+1.0 \mathrm{~g}$ sea sand per $\mathrm{ml}$ suspension. The homogenate was dried under reduced pressure and resuspended in $1 \mathrm{ml}$ of $50 \mathrm{mM}$ citric acid-trisodium citrate buffer $(\mathrm{pH} \mathrm{4.8)}$. A portion $(100 \mu \mathrm{l})$ was hydrolyzed ( $2 \mathrm{~h}$ in $2 \mathrm{M}$ trifluoroacetic acid, $120^{\circ} \mathrm{C}$ ) for scintillation counting; the remainder $(900 \mu \mathrm{l})$ was incubated for $2 \mathrm{~h}$ at $37^{\circ} \mathrm{C}$ with $14 \mathrm{I} . \mathrm{U}$. amyloglucosidase (Boehringer, Mannheim, F.R.G.) and centrifuged. Aliquots of the supernatant were used for scintillation counting and for thin-layer chromatography.

\section{Results and Discussion}

Growth characteristics of Nostoc spec. from Peltigera horizontalis

In liquid culture Nostoc spec. grew in clusters of filaments consisting of chains of bead-like cells and/or of more or less stretched filaments with almost no constrictions between the cells. The ratio of these two forms, both of which contained heterocysts, was variable and could not be correlated with any specific culture condition. In the stationary phase the filaments tended to disintegrate into single cells, probably akinetes. This observation as well as the occurrence of different types of filaments are in agreement with reports 


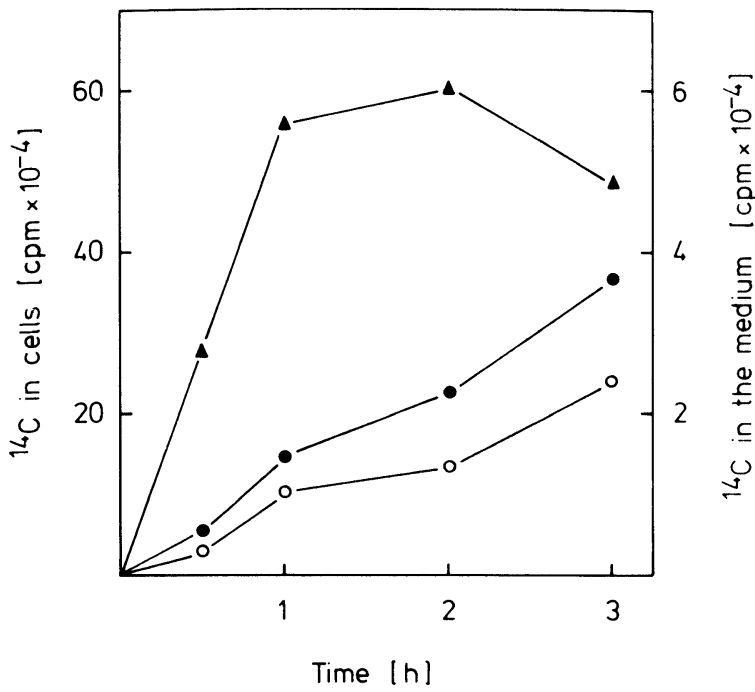

Fig. 1. Time course of ${ }^{14} \mathrm{C}$-labelling of cells and of excretion products of Nostoc spec. $\Delta-\mathbf{\Delta}$, radioactivity in cells; $\bullet-\bullet$, radioactivity in the medium; $\mathrm{O} \longrightarrow \mathrm{O}$, radioactivity of uncharged material in the medium. The initial rate of ${ }^{14} \mathrm{CO}_{2}$ assimilation was $47.6 \mu \mathrm{mol} \cdot \mathrm{h}^{-1} \cdot(\mathrm{g} \text { wet wt. })^{-1}$ equivalent to $122 \mu \mathrm{mol} \cdot \mathrm{h}^{-1} \cdot(\mathrm{mg} \text { chlorophyll })^{-1}$.

on Nostoc isolated from different species of Peltigera [11,12]. The growth proceeded logarithmically up to a density of $0.6 \mathrm{~g} / \mathrm{l}$ dry weight with a doubling time of 1.33 days; in the stationary phase a maximum yield of $2.9 \mathrm{~g} / \mathrm{l}$ dry weight was obtained.

Kinetics of ${ }^{14} \mathrm{CO}_{2}$ assimilation; analysis of excretion products; $\mathrm{pH}$ dependence of excretion

${ }^{14} \mathrm{CO}_{2}$ fixation proceeded in a linear fashion for $1 \mathrm{~h}$ (Fig. 1); later it decreased, perhaps because of depletion of $\mathrm{CO}_{2}$. Labeled products accumulated in the medium with a constant rate through $3 \mathrm{~h}$; in several experiments, after $1 \mathrm{~h}$ of assimilation, between 1 and $3.4 \%$ of total fixed ${ }^{14} \mathrm{C}$ were found to be released. About one third of the excreted radioactivity was bound to ion exchangers (Fig. 1). Thin-layer-chromatographic analysis of the remaining two thirds uncharged material yielded a complex pattern (Fig. 2a), generally with two conspicous peaks, one at the origin and the other with a relative mobility similar to glucose. The ratio of the two was variable and seemed to be in favour of the immobile material with younger cultures.
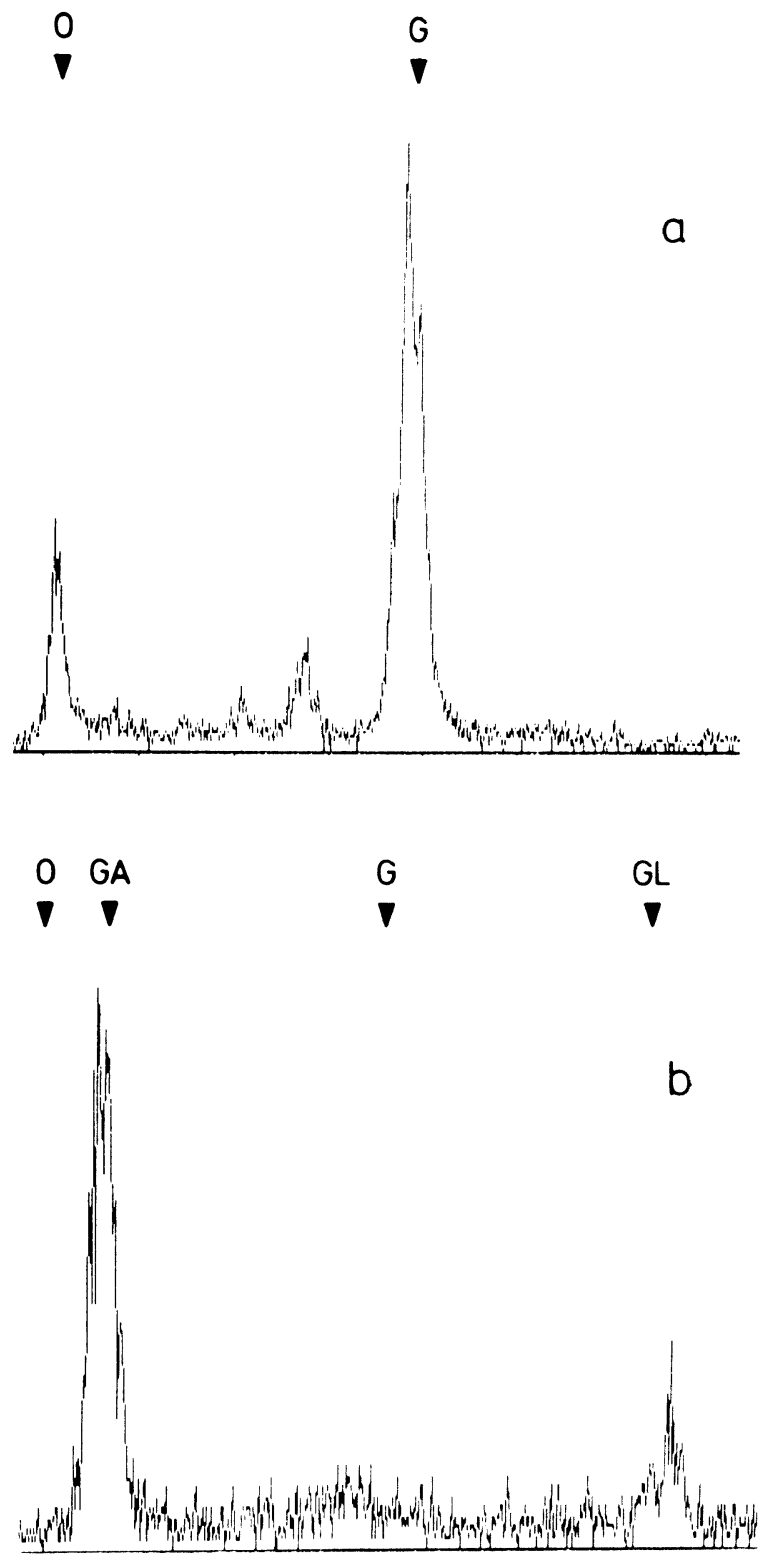

Fig. 2. Scans for radioactivity of thin-layer chromatograms.

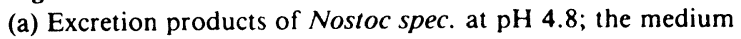
was treated with mixed ion-exchangers before separation. (b) Analysis of the peak at the position of glucose in (a). The peak material was eluted and incubated in a total volume of $0.6 \mathrm{ml}$ $17 \mathrm{mM} \mathrm{Na}$-acetate buffer (pH 5.6) with 62 I.U. glucose oxidase (Boehringer, Mannheim, F.R.G.) for $90 \mathrm{~min}$ at $37^{\circ} \mathrm{C}$, treated with cation exchanger (Serdolit CS-2, $\mathrm{H}^{+}$-form, Serva, Heidelberg, F.R.G.) and was chromatographed. The positions of reference substances are indicated: G, glucose; GA, gluconic acid; $\mathrm{GL}$, gluconolactone; $\mathrm{O}$, origin. 
When the putative glucose peak was eluted and treated with glucose oxidase, the major products corresponded to gluconolactone and gluconic acid (Fig. 2b). This is strong evidence for glucose as an excretion product of the cultured Nostoc spec. The percentage of total fixed ${ }^{14} \mathrm{CO}_{2}$ released as glucose was small, however, and varied between 0.04 and $0.8 \%$ after $1 \mathrm{~h}$ of assimilation in seven experiments. These results show that the photobiont is capable of releasing glucose also in the absence of the fungus, though in small amounts. Little excretion by cultured Nostoc spec. from Peltigera polydactyla has been observed also by Green and Smith [4]; they did not detect, however, glucose as an excretion product.

Buffer of pH 4.8 had been used in the preceding experiments, since an acidic $\mathrm{pH}$ was expected to favor sugar excretion as in the case of symbiotic Chlorellae $[6,8,13]$. Variation of the $\mathrm{pH}$ in the

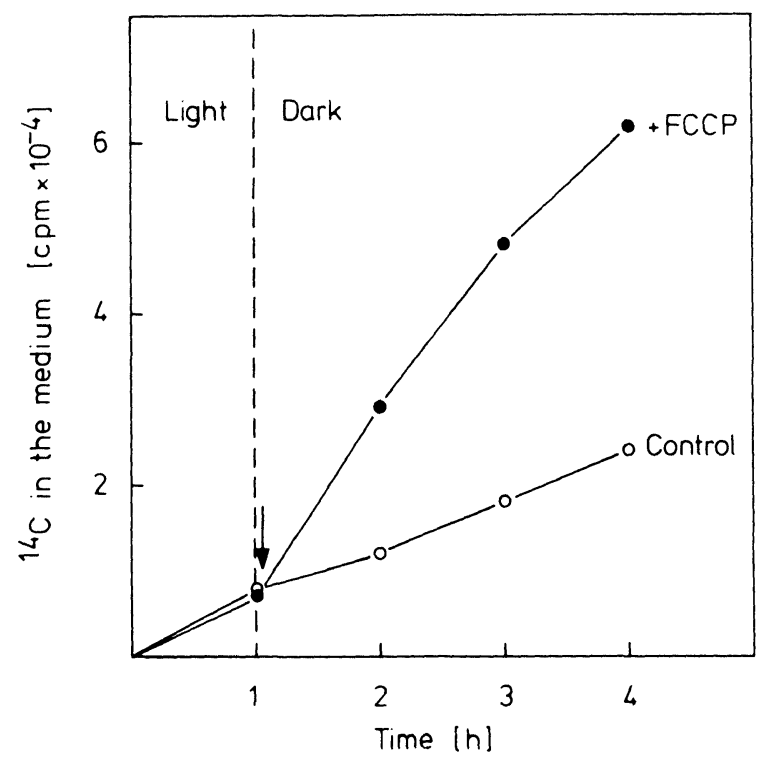

Fig. 3. The effect of FCCP on release of radioactive material by cells of Nostoc spec. in the dark. After $1 \mathrm{~h}$ of ${ }^{14} \mathrm{CO}_{2}$ assimilation (see Material and Methods) the cells were sedimented by centrifugation, resuspended in $0.5 \mathrm{ml}$ fresh buffer, transferred to a darkened test tube with air as gas phase and were shaken. Every hour the medium was removed for counting and was replaced by fresh buffer. The cumulated counts are plotted in the graph. At the beginning of the dark phase FCCP was added in ethanolic solution (final concentration $10^{-5} \mathrm{M}$ ), to the control ethanol only. The radioactivity recovered in the cells at the end of the dark phase was $256100 \mathrm{cpm}$ in the control and $231960 \mathrm{cpm}$ in the sample with FCCP. range of $\mathrm{pH} 4.8-7.8$, however, did not reveal a clear optimum, neither for total excreted material nor for excreted glucose (data not shown).

\section{The influence of FCCP on glucose excretion}

To see whether the release of glucose was energy-dependent, eventually due to an active

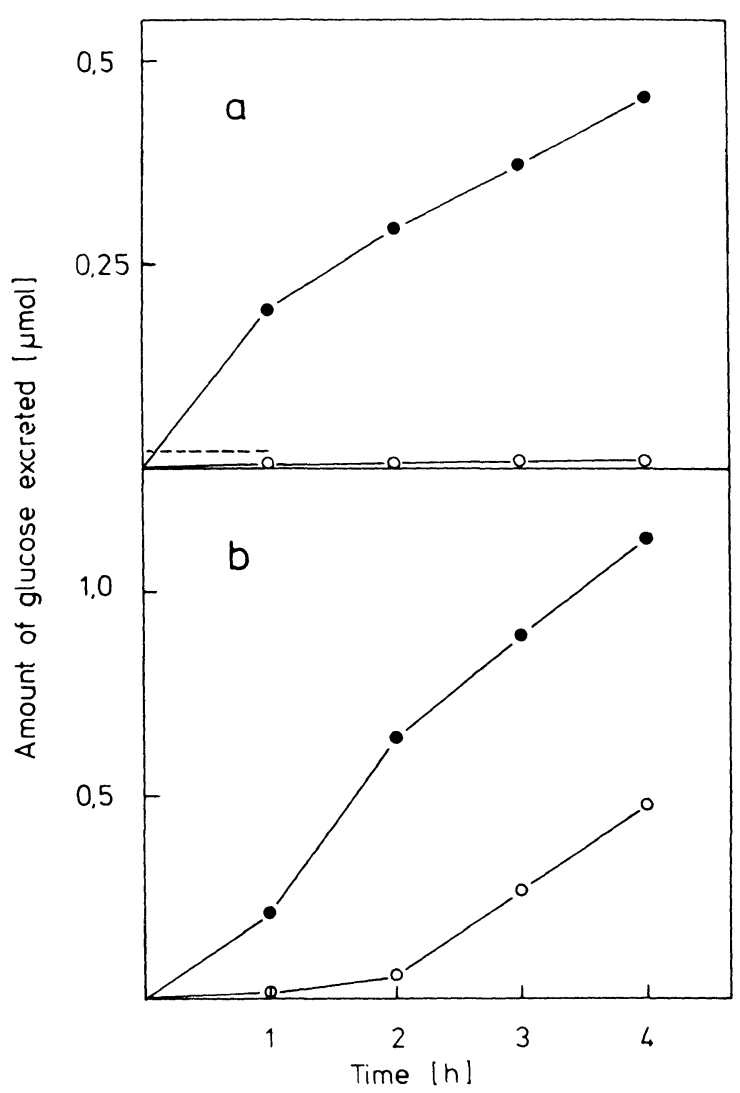

Fig. 4. Kinetics of glucose release from two Nostoc species in the presence $(-\infty)$ and absence $(\mathrm{O}-\mathrm{O})$ of FCCP. (a) Symbiotic Nostoc spec.; (b) Nostoc punctiforme. In a 100-ml Erlenmeyer flask, $600 \mathrm{mg}$ filaments (wet weight) suspended in $10 \mathrm{ml}$ of $50 \mathrm{mM}$ citric acid-trisodium citrate buffer ( $\mathrm{pH}$ 4.8) were shaken in the dark with air as gas phase. After every hour, the suspension was centrifuged, the supernatant was taken for the enzymatic glucose determination (see Material and Methods), and the pellet was resuspended in fresh buffer. FCCP dissolved in ethanol was included in the suspension buffer to give a final concentration of $10^{-5} \mathrm{M}$; the control contained the corresponding amount of ethanol only. The cumulated amounts of glucose are plotted in the graph. The dashed line in (a) indicates the pool of intracellular glucose + glucose 6-phosphate, which was determined from cells taken at the beginning of the experiment (see Material and Methods). 
Table I. Distribution of radioactivity after $1 \mathrm{~h}{ }^{14} \mathrm{CO}_{2}$ assimilation by Nostoc after a consecutive 4-h incubation of the cells in the dark in the presence of $10^{-5} \mathrm{M}$ FCCP. Filaments of $120 \mathrm{mg}$ wet weight suspended in $2 \mathrm{ml} 50 \mathrm{mM}$ citric acid-trisodium citrate buffer ( $\mathrm{pH}$ 4.8) were allowed to assimilate ${ }^{14} \mathrm{CO}_{2}$ for $1 \mathrm{~h}$ (see Material and Methods). The suspension was then divided into two halves; in one half the distribution of label between medium and cell fractions was determined immediately, in the other half after shaking for $4 \mathrm{~h}$ in the dark in the presence of $10^{-5} \mathrm{M} \mathrm{FCCP}\left(28^{\circ} \mathrm{C}\right.$, air as gas phase). Cell fractions were obtained as outlined in Material and Methods.

\begin{tabular}{lll}
\hline Fraction & \multicolumn{2}{l}{ Incubation condition } \\
\cline { 2 - 3 } & $\begin{array}{ll}1 \mathrm{~h} \mathrm{light},{ }^{14} \mathrm{CO}_{2} \\
(\mathrm{cpm})\end{array}$ & $\begin{array}{l}1 \mathrm{~h} \mathrm{light,} \\
\text { air, } 10^{-5} \mathrm{CO}_{2} ; 4 \mathrm{hCCP} \text { dark, } \\
(\mathrm{cpm})\end{array}$ \\
\hline Medium & 4050 & 92540 \\
Ethanol soluble & 12230 & 59150 \\
Ethanol insoluble & 207550 & 42900 \\
Degraded by amyloglucosidase & 178178 & 24233 \\
\hline
\end{tabular}

export step, experiments were carried out with the uncoupler FCCP. After $1 \mathrm{~h}$ of ${ }^{14} \mathrm{CO}_{2}$ assimilation the filaments were transferred into fresh buffer and the excretion of labeled material was followed in the dark, in the presence and absence of FCCP. Surprisingly, the uncoupler caused a several-fold increase in excreted radioactivity (Fig. 3), a large part of which $(56 \%)$ consisted of glucose as identified by thin-layer chromatography (cf. Fig. 2). In other experiments, unlabeled Nostoc spec. was incubated in the dark and extracellular glucose was determined enzymatically. In the presence of FCCP, glucose was released at a much higher rate as compared to the control (Fig. 4a). This effect was not specific for uncouplers like FCCP, since a several-fold stimulation of glucose efflux could be achieved also with $\mathrm{NaN}_{3}$, an inhibitor of respiration.

These observations support the idea that the glucose transport step is not an active process, but rather a passive one, e.g. a carrier-mediated diffusion. Such a passive process was suggested from work with thallus disks of Peltigera polydactyla, in which dinitrophenol and sodium azide showed no effect on the transfer of algal photosynthate to the fungus $[14 ; \mathrm{cf}$. 15]. In contrast, an energy requirement for the release of glucose, probably in the transport step proper, was indicated for a Chlorella symbiotic with a freshwater sponge [8].

Which pools are feeding the FCCP-induced glucose efflux? In the course of $4 \mathrm{~h}, 600 \mathrm{mg}$ (wet weight) Nostoc spec. had excreted $0.46 \mu \mathrm{mol}$ of glucose (Fig. 4a), whereas the pool of cellular glu- cose + glucose 6-phosphate at the beginning was only $0.022 \mu \mathrm{mol}$ (Fig. $4 \mathrm{a}$, dotted line). From this it is evident that some glucose precursor has to be degraded, probably an intracellular glucan. Experimental evidence for this was obtained by determining enzymatically the amount of labeled glucan (i) after a period of ${ }^{14} \mathrm{CO}_{2}$ assimilation and (ii) after an additional incubation in the dark in the presence of FCCP. Table I shows that after $1 \mathrm{~h}$ of ${ }^{14} \mathrm{CO}_{2}$ assimilation most of the label was recovered in insoluble material. Of this, $86 \%$ were degraded to glucose by amyloglucosidase. The insoluble cell fraction, therefore, seems to consist largely of a starch- or glykogen-like polysaccharide [16]. At the end of the incubation in the dark, this labeled glucan had diminished drastically with a concomitant increase of radioactivity in the medium and in the soluble cellular material (Table I). Thin-layer chromatographic analysis revealed $\left[{ }^{14} \mathrm{C}\right]$ glucose as a major component in the medium ( $49 \%$ of the medium's radioactivity). Another experiment gave a similar result. Thus, a glucan seems to be the source of the excreted glucose. Evidence for a glucan as an intermediate stage in the flow of carbon from the lichenized Nostoc to the fungus has been presented by Hill $[17,18]$.

The reason for the strong increase in glucose efflux caused by FCCP (Figs. 3 and $4 a$ ) is unclear. One could imagine that in Nostoc spec. a turnover of glucan occurs [17,18, cf.19] and that this turnover is unbalanced. A lower rate of glucan synthesis might be caused by an increased level of phosphate in the uncoupled state, since phosphate 
allosterically inhibits ADP-glucose pyrophosphorylase, the key enzyme of glucan biosynthesis $[20,21]$. Alternatively or in addition, the rate of glucan degradation might be increased by still unknown mechanisms [cf.22].

\section{Is the release of glucose specific for symbiotic Nostoc species?}

When two free-living species of cyanobacteria were tested for glucose release, one (Nostoc muscorum) was found to be incompetent and the other (Nostoc punctiforme) showed a release which could be stimulated by FCCP similar as in the symbiotic Nostoc spec., at least during the first $2 \mathrm{~h}$ (Fig. 4b). The ability for glucose release, therefore, is not a special character of symbiotic strains of cyanobacteria. The close relationship between symbiotic Nostoc spec. and free-living Nostoc punctiforme already suggested on grounds of their morphology [cf. 23] and life cycles [12] is further underlined by their common capability for glucose release.

\section{Acknowledgement}

This work was supported by the Deutsche Forschungsgemeinschaft. Thanks are due to Dr. W. Lockau for critical reading of the manuscript.

\section{References}

1 E.A. Drew and D.C. Smith, Studies in the physiology of lichens VIII. Movement of glucose from alga to fungus during photosynthesis in the thallus of Peltigera polydactyla. New Phytol., 66 (1967) 389-400.

2 D.J. Hill and D.C. Smith, Lichen physiology. XII. The “inhibition technique". New Phytol., 71 (1972) 15-30.

3 D.H.S. Richardson, D.J. Hill and D.C. Smith, Lichen physiology. XI. The role of the alga in determining the patterns of carbohydrate movement between lichen symbionts. New Phytol., 67 (1986) 469-486.

4 G.A. Green and D.C. Smith, Lichen physiology. XIV. Differences between lichen algae in symbiosis and in isolation. New Phytol., 73 (1974) 753-766.

5 E.A. Drew and D.C. Smith, Studies in the physiology of lichens. VII. The physiology of the Nostoc symbiont of Peltigera polydactyla compared with cultured and freeliving forms. New Phytol., 66 (1967) 379-388.

6 B. Matzke, E. Schwarzmeier and E. Loos, Maltose excretion by the symbiotic Chlorella of the heliozoan Acanthocystis turfacea. Planta, 181 (1990) 593-598.

7 R.Y. Stanier, R. Kunisawa, M. Mandel and G. CohenBazire, Purification and properties of unicellular blue- green algae (order Chroococcales). Bacteriol. Rev., 35 (1971) 171-205.

8 A. Fischer, D. Meindl and E. Loos, Glucose excretion by the symbiotic Chlorella of Spongilla fluviatilis. Planta, 170 (1989) 251-256.

9 H.U. Bergmeyer, E. Bernt, F. Schmidt and H. Stork, DGlucose:Bestimmung mit Hexokinase and Glucose-6phosphat-Dehydrogenase, in: H.U. Bergmeyer (Ed.), Methoden der Enzymatischen Analyse, Vol. II, Verlag Chemie, 1974, pp. 1241-1246.

10 R.L. Bieleski, Sugar alcohols, in: F.A. Loewus and W. Tanner (Eds.), Encyclopedia of Plant Physiology, New Series, Vol. 13A, Springer-Verlag, 1982, pp. 158-192.

11 B. Bergmann and L. Hällbom, Nostoc of Peltigera canina when lichenized and isolated. Can. J. Bot., 60 (1982) 2092 -2098 .

12 J.C. Boissière, N.C. Boissière, P. Champion-Arnaud and R. Lallemant, Le cycle des Nostoc des genres Peltigera et Collema en cultures in vitro et dans le thalle lichénique. Can. J. Bot., 65 (1987) 1468-1477.

13 L. Muscatine, Symbiosis of hydra and algae. III. Extracellular products of the algae. Comp. Biochem. Physiol., 16 (1965) 77-92.

14 D.C. Smith, Symbiosis and the biology of lichenised fungi, in Symbiosis, 29th Symp. Soc. Exp. Biol., Cambridge University Press, London, 1975, pp. 373-405.

15 S. Chambers, M. Morris and D.C. Smith, Lichen physiology. XV. The effect of digitonin and other treatments on biotrophic transport of glucose from alga to fungus in Peltigera polydactyla. New Phytol., 76 (1976) 485-500.

16 J. H. Pazur and T. Ando, The action of an amyloglucosidase of Aspergillus niger on starch and maltose-oligosaccharides. J. Biol. Chem., 234 (1959) 1966-1970.

17 D.J. Hill, The movement of carbohydrate from the alga to the fungus in the lichen Peltigera polydactyla. New Phytol., 71 (1972) 31-39.

18 D.J. Hill, The physiology of lichen symbiosis, in: D.H. Brown, D.L. Hawksworth and R.H. Bailey (Eds.), Lichenology: Progress and Problems, Academic Press, 1976, pp. 457-496.

19 M. Lehmann and G. Wöber, Accumulation, mobilization and turnover of glycogen in the blue-green bacterium Anacystis nidulans. Arch. Microbiol., 111 (1976) 93-97.

20 J. Preiss, H.P. Ghosh and J. Wittkop, Regulation of the biosynthesis of starch in spinach leaf chloroplasts, in: T.W. Goodwin (Ed.), Biochemistry of Chloroplasts, Vol. II, Academic Press, 1967, pp. 131-153.

21 C. Levi and J. Preiss, Regulatory properties of the ADPglucose pyrophosphorylase of the blue-green bacterium Synechococcus 6301. Plant Physiol., 58 (1976) 753-756.

22 A.J. Smith, Modes of cyanobacterial carbon metabolism, in: N.G. Carr and B.A. Whitton (Eds.), The Biology of Cyanobacteria, Botanical Monographs, Vol. 19, Blackwell Scientific Publications, 1982, pp. 47-85.

23 L. Geitler, Cyanophyceae, in: R. Kolkwitz (Ed.), Dr. L. Rabenhorst's Kryptogamenflora von Deutschland, Österreich und der Schweiz, Vol. 14, Akademische Verlagsgesellschaft m.b.H., 1932, pp. 1-1196. 